\title{
Some types of mycorrhizae in the humus layer of conifer forests in Finland
}

\author{
V. Hintikka \\ Finnish Forest Research Institute, Unioninkatu 40 A \\ SF-00170 Helsinki 17, Finland
}

When one investigates the fungus flora of the moss and humus layers of conifer forests in South and Central Finland, one finds easily numerous types of mycorrhizae, mycelia, sclerotia, and rhizomorphs, which are rather easy to recognize, but difficult to identify as belonging to a certain fungus species. Most easily are seen the bright yellow mycorrhizae evidently formed by Corticium bicolor (MIKOLA 1962)-as well as black mycorrhizae and sclerotia of of Cenococcum graniforme (MIkOLA 1948). Also easily recognizable and common are mycorrhizae of Paxillus involutus (LAIHO 1970).

In dry conifer forests one finds often in uppermost humus layers and from under the moss mycorrhizae, which resemble those of Corticium, but the color of which is reddish brown (Fig. 1). They are conspicuous just beneath moss carpet in Vaccinium type of pine stands on sandy soils. Numerous attempts to isolate from mycorrhizae by surface sterilization with $\mathrm{H}_{2} \mathrm{O}_{2}$, sublimate, and calcium hypochlorite were made, but without success. In the autumn it was found, however, that the typical reddish-brown mycorrhizae in several cases coalesced without difference into the basal tomentum of basidiocarps of Cortinarius semisanguineus Fr. Near the bases of fruit bodies of this species one sees very often this type of reddish-brown mycorrhizae, especially in places with a welldeveloped thick moss layer (Pleurozium Schreberi, Hylocumium proliferum).

The obtaining an aseptic culture of Cortinarius semisanguineus proved to be difficult.
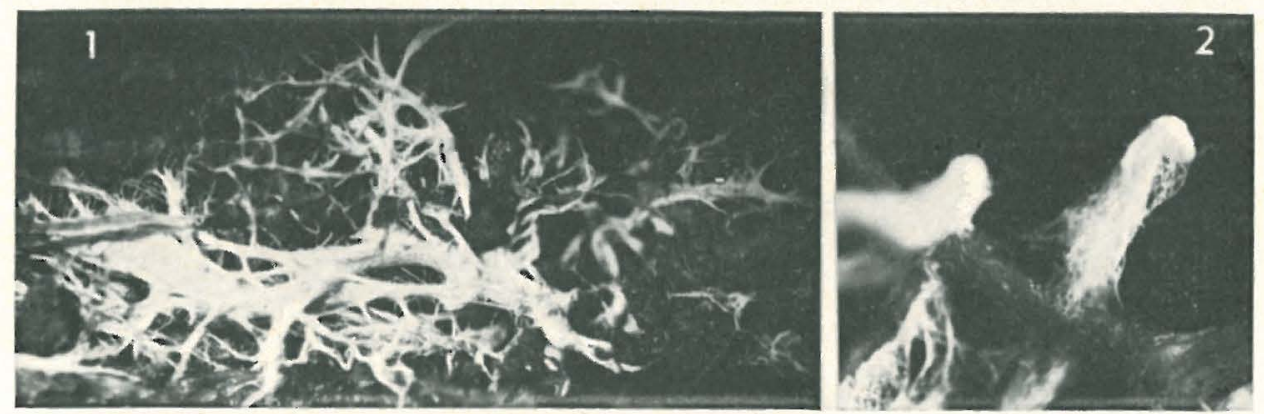

Fig. 1. Reddish-brown mycorrhizae of pine evidently formed by Cortinarius semisanguineus in the humus layer of Vaccinium type pine stand. - Fig. 2, Pine mycorrhizae formed by Cortinarius semisanguineus in aseptic synthese experiment. 
Only after several hundreds of attempts a piece of tissue taken in the cap tissue began to grow slowly on Hagem agar, forming a reddish-brown mycelium, the color of which matched closely to that found in mycorrhizas in nature.

With the pure culture of this species I made some synthesis experiments with pine seedlings using the technique of Melin (1936). Fig. 2 depicts mycorrhizae, which were similar to those seen in nature, although the net of Hartig was developed rather poorly (Fig. 3).

Cortinarius semisanguineus is regarded to form mycorrhizae with spruce (Romell 1938) and with birch and willows (LANGE 1957) based on field observations. Aseptic synthese experiments seem not to be reported earlier.

Another characteristic mycelium and mycorrhizae are found constantly together with a Hebeloma-species, which is tentatively identified as Hebeloma longicaudum (Fr.)

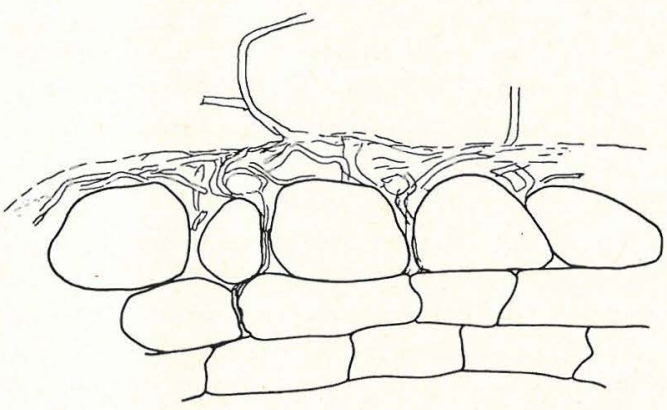

Fig. 3. Longitudinal section of short root of pine grown aseptically with mycelium of Cortinarius semisanguineus. 19. 4. 1963. ss. Lange. This species is not uncommon in dry spruce - pine forests on sandy soil with a well-developed moss (Pleurozium Schreberi, Hylocomium proliferum, Dicranum undulatum) layer, and under the basidiocarps is to be found abundantly white mycelium and mycorrhizae (Fig. 4 and 5 ). This species is easily isolated into aseptic culture from basidiocarps, and the mycelium is pure white with abundant aerial mycelium. In synthesis experiments with pine and spruce mycorrhizae were developed, but the Harting's net was developed poorly.

Species of Hebeloma are known to form mycorrhizae with over a dozen tree species (Shemakhanova 1956, Trappe 1962). $H$. longicaudum is reported to form mycorrhizae in nature with Pinus silvestris (BECKER 1956), Betula, Populus and Salix (Trappe 1962), and in synthesis experiments with Pinus virginiana (Hacskaylo \& BRUchet 1972).

A couple of determinations of oxygen uptake of humus colonized by mycelium of $\mathrm{He}$ beloma (as in Fig. 4) were made with a Warburg apparatus. Bath temperature was $15^{\circ}$ and ca. $500 \mathrm{mg}$ humus was used in the flasks. Compared with surrounding humus at the same depth, the mycelial humus proved to be definitely more active.

The observations reported above suggest that the identification of mycelia and mycorrhizae in the field can be carried evidently further than present-day information suggests by studying the correlation of basidiocarps and visible mycorrhizae and mycelia in the humus. However, in addition is needed asep-
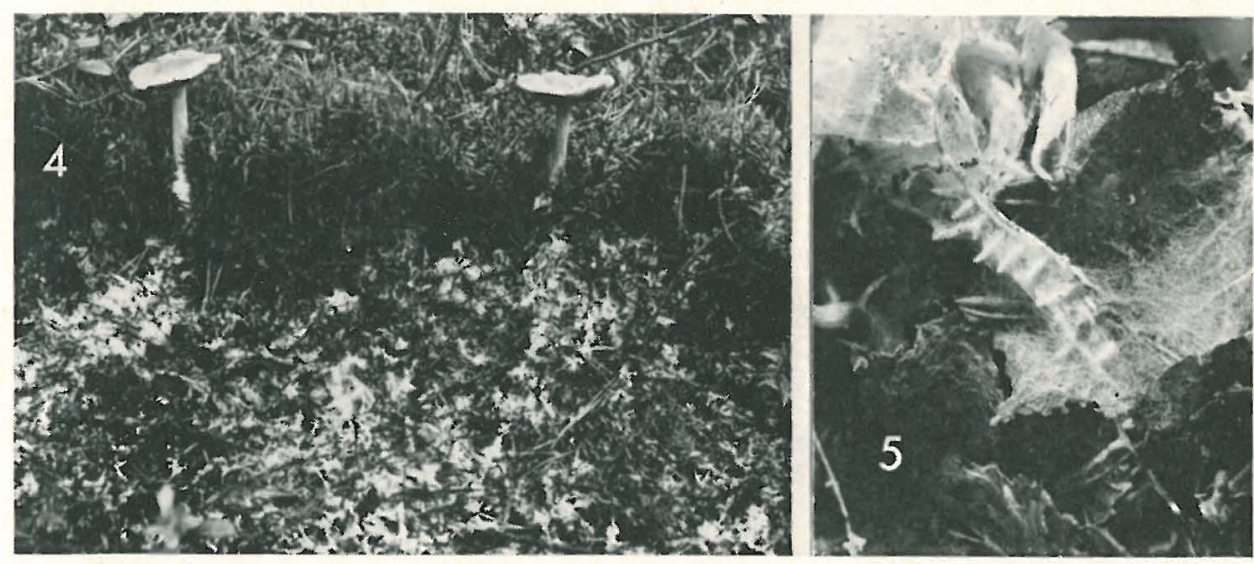

Fig. 4. White mycelium around basidiocarps of Hebeloma longicaudum evidently belonging to this species. - Fig. 5. Mycorrhizae in nature, evidently formed by Hebeloma. 
tic synthesis experiments to correlate causally these facts. For instance, one can find under the basidiocarps of Cortinarius cinnamomeus mycorrhizae, which are similar to those of
C. semisanguineus, but pale citrine yellow in color. Under other species of Cortinarius (especially C. armillatus) one can easily find characteristic mycorrhizae, too.

\section{REFERENCES}

Becker, V. 1956: Observations sur l'ecologie des champignous supérieurs. - Bull. Soc. d'Histoire Nat. du Douds, 58, 14-128.

Hagskaylo, E. and. Brughet, G. 1972: Hebelomas as mycorrhizal fungi. - Bull. Torrey Bot. Club. 99, 17-20.

Lano, O. 1970: Paxillus involutus as a mycorrhizal symbiont of forest trees. - Acta Forest. Fenn. 106, 72 pp.

LANGe, M. 1957: Macromycetes. Part III. Medid, om Grønland 148, (2), 1-125.

Melin, E. 1936: Methoden der experimentellen Untersuchung mykotropher Pflanzen. Handbuch der biol. Arbeitsmethoden, herausg. von E. Abderhalden, Abt. XI, Teil 4, S. 1015-1108.

Mikola, P. 1948: On the physiology and ecology of Cenococcum graniforme, especially as a mycorrhizal fungus of birch. - Comm. Inst. Forest. Fenn. 36, 3.
- 1962: The bright yellow mycorrhiza of raw humus. - Proc. IUfro 13th Congress, Vienna, Part 2, Vol. 1.

RomelL, L. 1938: A trenching experiment in spruce forest and ist bearing on problems of mycotrophy. - Sv. Bot. Tidskr. 32, 8999.

Shemakhanova, N. M. 1956: Hebeloma crustuliniforme (Bull.) Fr. mycorrhizaformer with oak (in Russian). - Mikrobiologiya. 25, $57-60$.

Trappe, J. 1962: Fungus associates of ectotrophic mycorrhizae. - Bot. Rev. 28, 538-606.

$\mathrm{Z}_{\mathrm{AK}}$, B. 1971: Characterization and identification of Douglas Fir mycorrhizae. - U. S. Dept. of. Agric. Forest Serv. Misc. Publ. 1189 Proc. of the First North American Conference on mycorrhizae, ed. by E. Hacscaylo, pp. $38-53$. 